\title{
HIV Surveillance in India: An Overview \& Implications for Future
}

\author{
Divya Persai* \\ public health fiooundation of india, Delhi, India
}

\section{Objective}

To study and analyze the surveillance activities in HIV prevention and control in India.

\section{Introduction}

Surveillance of risky behaviors of HIV infection and its manifest diseases has provided a better understanding of the complex nature of the HIV epidemic in India. However, little attempt is made to analyze progress of these surveillance activities.

\section{Methods}

A review \& analysis of surveillance activities undertaken in India were done. Pub-med, cohrane library and peer-reviewed journals were referred for relevant literature.

\section{Results}

Initially, medical officers from multiple types of government hospitals in India were expected to report AIDS cases, including deaths. However, this reporting mechanism was inadequate, complicated by many disparate types of reporting units with incomplete and delayed reports. Therefore AIDS case reporting has been replaced by HIV case reporting from the 4532 Integrated Counseling and Testing Centers. Newer surveillance strategies like Behavior sentinel surveillance measure behaviors that affect risk for acquiring HIV. However, behavioral and biological data are resource-intensive and time-consuming. Facility-based sero-surveillance (also called HIV Sentinel Surveillance or HSS) has emerged as the key surveillance strategy for HIV/AIDS in India. Starting with 55 urban sentinel sites HIV Sentinel Surveillance expanded to 1215 in 1994. Most of these pre-selected sites were antenatal clinics but also included sexually transmitted infection clinics and special facilities. Subsequent expansion of high-risk group sites has improved the representation of all sub-populations in HSS. While stigma against most high-risk populations and HIV-positive people continues, it has lessened as shown by the behavioral surveys. Also, accessibility to testing sites has increased with increased availability of care and treatment options for infected individuals.

\section{Conclusions}

While acknowledging the vastness and diversity of India, the key limitations remain suboptimal coverage and lack of representativeness surveillance data. Moreover, due to selection bias, the populations selected for HSS at targeted intervention sites may not represent everyone in that community. There is lack of national information system to collect HIV testing information from the private sector. Further efforts are needed to improve HIV surveillance data and usage of this data to predict the epidemic.

\section{Keywords}

Surveillance; HIV; India

\section{References}

1. Department of AIDS Control, Ministry of Health and Family Welfare, National AIDS Control Organization (NACO) Annual Report, 20092010. www.nacoonline.org/

2. National Family Health Survey, India: http://www.nfhsindia.org/

3. WHO case definitions of HIV for surveillance and revised clinical staging and immunological classification of HIV-related disease in adults and children; ISBN: 978924159562 9. August 2006.

4. Family Health International (FHI) website: FHI-conducted BSS and IBBSS Reports 1989-2009. www.fhi.org/en/HIVAIDS/pub/survreports/index.htm

5. Bachani D, Sogarwal R, Rao KS. A population bases survey on HIV prevalence in Nagaland, India. SAARC J Tuber Lung Dis HIV/AIDS 2009 (1)1-11.

6. The World Health Organization's global strategy for prevention and assessment of HIV drug resistance; Diane E Bennett, S Bertagnolio, D Sutherland, C F Gilks: Antiviral Therapy 13 Suppl 2:1-13; 2008 International Medical Press:1359-6535.

7. Technical Consultation to Review HIV Surveillance in India, 23-25 April 2008, New Delhi, India. WHO/SEAR and NACO. SEA/AIDS/182. Available at www.searo.int/hiv-aids publications.

8. HIV/AIDS epidemic in India: risk factors, risk behavior \& strategies for prevention \& control; Godbole S, Mehendale S: Indian J Med Res 121, April 2005(356-368).

9. Stigma in the HIV/AIDS epidemic: A review of the literature and recommendations for the way forward; Mahajan A P, Sayles JN, Patel VA, Remien RH, Ortiz D, Szekeres G, Coates TJ. AIDS 2008 August; 22(Suppl 2): S67-S79.

10. Epidemiological analysis of the quality of HIV sero-surveillance in the world: how well do we track the epidemic?: Walker n, GarciaCalleja JM, Asamoah-Odei E, Poumerol G, Lazzari S, Ghys PD, Scwartlander B, Stanecki KA. AIDS 2001 Aug 17; 15(12):1545-54.

11. Advances and future directions in HIV surveillance in low- and middle-income countries. Diaz T, Garcia-Calleja JM, Ghys PD, Sabin K. Curr Opin HIV AIDS. 2009 Jul;4 (4):253-9.
*Divya Persai
E-mail: dpersai@gmail.com 